\title{
The uranium isotopic composition of lacustrine Holocene stromatolites from the East African Rift System
}

\author{
ASHLEY N. MARTIN ${ }^{1}$, MONIKA MARKOWSKA ${ }^{2}$, \\ ANNETT JUNGINGER ${ }^{3}$ AND STEFAN WEYER ${ }^{4}$ \\ ${ }^{1}$ Leibniz University Hannover, Institute for Mineralogy \\ ${ }^{2}$ Max Planck Institute for Chemistry \\ ${ }^{3}$ University of Tübingen \\ ${ }^{4}$ Wilhelm Leibniz Universität Hannover, Institut für Mineralogie \\ Presenting Author: a.martin@mineralogie.uni-hannover.de
}

Microbial carbonates represent valuable geochemical archives for the redox state of early Earth and are ideal candidiates for the application of redox-sensitive, non-traditional isotopic systems, such as uranium $\left({ }^{238} \mathrm{U} /{ }^{235} \mathrm{U}\right)$. Many important early examples of Archean stromatolites formed in volcanically-active settings, e.g., the 3.5 Ga Dresser Formation. Modern volcanic lakes also present favourable conditions for microbial carbonate precipitation and an oppurtunity to improve our understanding of the controls on isotopic proxy signals recorded in microbial carbonates. Here we measure the stable isotopic $\left(\delta^{13} \mathrm{C}, \delta^{18} \mathrm{O}\right)$, trace element and $U$ isotopic composition $\left(\delta^{234} U, \delta^{238} U\right)$ of Holocene microbialites (three stromatolites and one oncolite) from Lake Chew Bahir, Ethiopia, located in the East African Rift System. Groundwater, lake waters, and river waters from the area were also analysed to assess controls on isotopic signals. Microbialite $\delta^{238} \mathrm{U}$ ranged from -0.48 to $+0.03 \%$ and vary both between samples (of different age and morphology) and within samples according to the alternating laminae of micrite and sparite. Lake waters exhibited crustal $\delta^{238} U$ (ca. $-0.3 \%$ ) and groundwater $\delta^{238} \mathrm{U}$ varied from -0.68 to $-0.07 \%$. As the $U$ concentrations in rivers $(<1 \mathrm{ppb})$ were at least an order of magnitude less than those of groundwaters, they were not deemed to be important sources of $U$. We posit that variations in microbialite $\delta^{238} \mathrm{U}$ are controlled by variations of groundwater discharge into the lake, which in turn may be related to past changes in lake level and climate. Although the groundwater influence on the microbialites appears to be high, the effect of lacustrine processes is also reflected in the strong correlation between microbialite $\delta^{13} \mathrm{C}$ and $\delta^{18} \mathrm{O}$, cyclical variations of $\mathrm{Fe}$ and $\mathrm{Mn}$ in microbialite laminae, higher microbialite $\delta^{238} \mathrm{U}$ than those of the water samples, and a correlation between $\delta^{238} \mathrm{U}$ and Mo concentrations. Our findings demonstrate the microbial activity in modern volcanic lakes can produce large variations in $\delta^{238} \mathrm{U}$ and may be useful for understanding $\delta^{238} \mathrm{U}$ records from ancient stromatolites that formed in similar settings. 